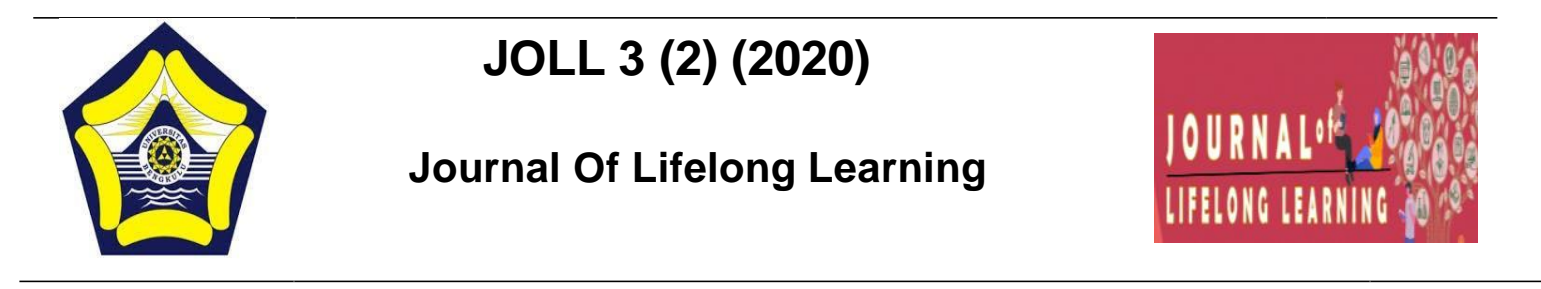

\title{
PERAN TUTOR DALAM PELAKSANAAN METODE QIRO'ATI DI TPQ PAUDIT AL HASANAH
}

\section{Ari Angga ${ }^{1}$, Suardi Jasma ${ }^{2}$, Ririn Gusti ${ }^{3}$}

${ }^{1}$ Ari Angga MZ, Universitas Bengkulu, Indonesia, Prayers2510@gmail.com

${ }^{2}$ Suardi Jasma, Universitas Bengkulu, Indonesia, suardijasma@unib.ac.id

${ }^{3}$ Ririn Gusti, Universitas Bengkulu, Indonesia, riringusti@unib.ac.id

\begin{abstract}
Learning the Qur'an with the Qiro'ati method is the system and how to read it smoothly, quickly, precisely, correctly, and in tartil without having to be spelled. Then the implementation model is to use props for classical implementation which contains material that is in the pages of the volume book Qiro'ati. The instructor must conduct Qiro'ati education and training so as to obtain an official diploma that can be used to teach the Qiro'ati method. Then the purpose of this research is to find out what methods are used, how the learning process is, and to find out the supporting and inhibiting factors. This research uses descriptive qualitative research methods. The research was conducted at the Al-Qur'anah Education Park PAUDIT Al Hasanah Pagar Dewa Bengkulu City on March 5 to April 5, 2019. The subjects of the study were the head and coordinator of the TPQ itself and the TPQ PAUDIT teacher Al Hasanah Pagar Dewa Bengkulu City.
\end{abstract}

Keywords: Role of Tutors (Ustad / Ustadzah), Al Qur'an Learning, Qiro'ati Method

(C2020 DeptofNonformalEducationUNIB ISSN : 2715-9809

Addresscorrespondence:

Jl.W.R.Supratman,KandangLimun,MuaraBangkaHulu, KotaBengkulu,Bengkulu38371 


\section{PENDAHULUAN}

Pendidikan adalah bantuan atau pertolongan yang diberikan oleh seseorang kepada orang lain untuk mengembangkan dan memfungsionalkan rohani (pikir, rasa, karsa, cipta dan budi nurani) manusia, dan jasmani (pancaindera dan keterampilanketerampilan) manusia agar meningkat wawasan pengetahuannya, bertambah terampil sebagai bekal keberlangsungan hidup dan kehidupannya disertai akhlak mulia dan mandiri di tengah masyarakat (Brubacher dalam Musaheri 2007:48).

Pendidikan di Indonesia menurut Undang-Undang (UU) No. 2 Tahun 1989 dan PP No. 73 Tahun 1991, pendidikan diselenggarakan melalui dua jalur, yaitu jalur sekolah dan jalur luar sekolah. Pendidikan nonformal adalah pendidikan yang diselenggarakan di luar jalur (atau sistem) pendidikan sekolah, baik dilembagakan maupun tidak dilembagakan, yang tidak harus berjenjang dan berkesinambungan.

Dalam (UU) Sisdiknas Tahun 2003 istilah pendidikan formal, nonformal dan informal dipergunakan kembali. Dijelaskan bahwa pendidikan nonformal adalah jalur pendidikan di luar pendidikan formal yang dapat dilaksanakan secara terstruktur dan berjenjang. Sedangkan pendidikan informal adalah jalur pendidikan keluarga dan lingkungan.

Dengan demikian, dapat dikatakan bahwa pendidikan nonformal dilaksanakan di jalur nonformal dan informal. Satuan pendidikan nonformal terdiri atas lembaga kursus, lembaga pelatihan, kelompok belajar, pusat kegiatan belajar masyarakat, dan majelis taklim, serta satuan pendidikan yang sejenis (Musaheri, 2007:157).
Kemudian jika kita melihat ragam pendidikan di Indonesia pendidikan agama adalah bagian integral dari pendidikan nasional yang mana sebagai satu kesatuan. Dalam undang-undang RI No. 20 tahun 2003 dijelaskan bahwa:

Pendidikan nasional berfungsi mengembangkan kemampuan dan membentuk watak serta peradaban bangsa yang bermartabat dalam rangka mencerdaskan kehidupan bangsa, bertujuan untuk berkembangnya potensi peserta didik agar menjadi manusia yang beriman dan bertakwa kepada Tuhan yang Maha Esa, berakhlak mulia, sehat, berilmu, cakap, kreatif, mandiri dan menjadi warga negara yang demokratis serta bertanggung jawab.

Dari tujuan pendidikan nasional tersebut dapat dipahami bahwa salah satu ciri manusia Indonesia adalah beriman dan bertakwa serta berakhlak mulia. Tujuan ini hanya dapat dicapai melalui Pendidikan Agama yang intensif dan efektif (Daradjat, 2001:171).

Untuk hal ini pemerintah juga telah menetapkan peraturan tentang pendidikan keagamaan yaitu pada pasal 30 UndangUndang RI No. 20 tahun 2003 tentang sistem Pendidikan Nasional. Pada ayat 3 dan 4 pasal 30 undang-undang tersebut dijelaskan bahwa: "Pendidikan keagamaan dapat diselenggarakan pada jalur pendidikan formal, non formal dan informal. Pendidikan keagamaan berbentuk pendidikan diniyah, pesantren, dan bentuk lain yang sejenis (lihat: UU RI tentang Sisdiknas).

Dalam Peraturan Pemerintah No. 55 tahun 2007 pasal 24 ayat 2 tentang Pendidikan Agama dan Pendidikan Keagamaan menyatakan bahwa Pendidikan 
Al-Qur'an terdiri dari Taman Kanak-Kanak Al-Qur'an (TKA/TKQ), Taman Pendidikan Al-Qur'an (TPA/TPQ), Ta'limul Qur'an lil Aulad (TQA), dan bentuk lainnya yang sejenis.

Adanya peraturan tersebut menunjukkan bahwa pemerintah juga memberikan perhatian yang besar terhadap pendidikan agama. Realisasi dari peraturan tersebut salah satunya dapat dilihat dari berkembangnya sebuah lembaga pendidikan nonformal berupa TPQ (Taman Pendidikan Al-Qur'an) yaitu lembaga pendidikan nonformal keagamaan untuk anak usia sekolah dasar. Keberadaan TPQ diharapkan dapat menjadi salah satu alternatif untuk menghadapi tantangan yang tengah dihadapi umat Islam di Indonesia.

\section{METODE}

Metode yang digunakan dalam penelitian ini adalah metode kualitatif. Dalam penelitian ini peneliti berusaha untuk mengetahui bagaimana Peranan Tutor (Ustad dan Ustadzah) dalam menyampaikan pelaksanaan membaca Al-Qur'an dengan Metode Qiro'ati terhadap peserta didik di TPQ PAUDIT Al Hasanah Pagar Dewa Kota Bengkulu. Untuk mencari jawaban tersebut maka peneliti menggunakan penelitian kualitatif deskriptif.

Dalam melakukan penelitian membutuhkan alat yang disebut alat pengumpulan data dimana peneliti sebagai instrumen penelitian, yaitu peneliti menyimpulkan sendiri hasil penelitian dari pengumpulan data utama seperti data atau informasi melalui observasi, wawancara, dan studi dokumentasi.
Dalam hal ini penulis melakukan pengamatan secara langsung menuju objek atau tempat penelitian yang akan dilakukan yakni mengunjungi sembari melihat keadaan TPQ PAUDIT Al Hasanah Pagar Dewa Kota Bengkulu. Dari hasil pengamatan yang hanya bersifat sementara, penulis melihat dan menyimpulkan bahwasannya setiap sorenya di TPQ tersebut terjadi kegiatan atau proses belajar mengajar baca Al-Qur'an pada petang hari.

Proses pengumpulan data atau informasi melalui tatap muka antara pihak penanya (interviewer) dengan pihak yang ditanya atau penjawab (interviewee). Wawancara dilakukan penanya dengan menggunakan pedoman wawancara (interview guide).

Pada tahap wawancara ini nantinya penulis akan melakukan proses wawancara langsung kepada subyek penelitian guna mendapatkan informasi dan data yang akurat serta efisien sesuai dengan rumusan masalah dengan acuan kisi-kisi wawancara yang telah dipersiapkan sebelumnya. Adapun subyek penelitian yang nantinya akan dijadikan responden dalam proses wanwancaranya yakni kepala TPQ PAUDIT Al Hasanah Pagar Dewa Kota Bengkulu itu sendiri. Kemudian peneliti juga akan melakukan wawancara dengan beberapa orang guru atau tutor yang ikut dalam proses pelaksanaan baca Al-Qur'an di TPQ PAUDIT Al Hasanah Pagar Dewa Kota Bengkulu.

Adapun dokumentasi yang peneliti akan lakukan dalam penelitian ini adalah terkait dengan segala aktivitas dan proses pelaksanaan baca Al-Qur'an di TPQ PAUDIT Al Hasanah Pagar Dewa Kota Bengkulu. 
Dalam reduksi data ini peneliti mengambil data dari hasil wawancara dari pengurus TPQ dimana data yang diperoleh oleh peneliti bermaksud untuk mendapatkan jawaban atas permasalahan yang ada pada

\section{HASIL DAN PEMBAHASAN}

Untuk mendeskripsikan bagaimana proses kegiatan pembelajaran yang dilakukan tutor dalam menyampaikan pelaksanaan baca Al-Qur'an terhadap peserta didik di Taman

dan pada waktu serta tempat yang berbeda maka dapat disimpulkan bahwa benar adanya pelaksanaan pembelajaran baca Al-Qur'an di TPQ PAUDIT Al Hasanah Pagar Dewa Kota Bengkulu ini dengan menggunakan metode qiro'ati dengan proses penerapannya sebagai berikut, yakni dilakukan selama 60 menit dan terbagi menjadi 4 bagian, yaitu pertama, 15 menit pertama berupa penyampaian sedikit materi tambahan yang diberikan guru sesuai jilid masing-masing. 15 menit kedua yaitu guru mempraktekkan alat peraga. 15 menit ketiga yaitu setiap murid masing-masing antri membaca buku pedoman qiro'ati. Kemudian 15 menit yang tearkhir adalah kembali dengan menggunakan alat peraga dan juga nasihat pada peserta didik serta ditutup dengan doa.

\section{KESIMPULAN}

Dari hasil penelitian di lapangan tentang Peranan Tutor (Ustad dan Ustadzah) Dalam Menyampaikan Pelaksanaan Membaca Al-Qur'an Dengan Metode Qiro'ati Terhadap Peserta Didik di TPQ PAUDIT Al Hasanah Pagar Dewa Kota Bengkulu, berdasarkan rumusan masalah, tujuan penelitian, hasil penelitian dan pembahasan maka dapat disimpulkan bahwa bab I, baik itu tentang metode tutor Taman Pendidikan Al-Qur'an maupun faktor pendukung dan penghambat tutor dalam proses pelaksanaan baca Al-Qur'an di Taman Pendidikan Al-Qur'an (TPQ).

Pendidikan Al-Qur'an (TPQ) PAUDIT Al Hasanah Pagar Dewa Kota Bengkulu.

Temuan penelitian di lapangan diketahui bahwa berdasarkan wawancara yang dilakukan oleh peneliti kepada informan dengan pertanyaan yang sama metode ini dalam proses penerapannya sebagai berikut, yakni dilakukan selama 60 menit dan terbagi menjadi 4 sesi, yaitu pertama, 15 menit pertama berupa penyampaian sedikit materi tambahan yang diberikan guru sesuai jilid masing-masing. 15 menit kedua yaitu guru mempraktekkan alat peraga. 15 menit ketiga yaitu setiap murid masing-masing antri membaca buku pedoman qiro'ati. Kemudian 15 menit yang tearkhir adalah kembali dengan menggunakan alat peraga dan juga nasihat pada peserta didik serta ditutup dengan doa.

\section{REFERENSI}

Asmani. Dan Ma'mur Jamal. (2009) Manajemen Strategis Pendidikan Anak Usia Dini. Yogyakarta: Diva Pers.

Emzir. (2014). Metodologi Penelitian Kualitatif (Analisis Data). Jakarta : Rajawali Pers.

Hidayanto, Nur. (2013) Analisis Hasil Uji Kompetensi Pembelajaran Bahasa Inggris Dengan Model Logistik. Jurnal Kependidikan. 43(1) Hlm 6168.Hilman, Muhammad. (2018) Pengelolaan Program Kursus Bahasa Inggris pada Lembaga Kursus English Café Yogyakarta. Jurnal Pendidikan Luar Sekolah. 8 (2) hlm. 154-163. 
Kamil, Mustofa. (2012). Model Pendidikan dan Pelatihan (Konsep dan Aplikasi). Bandung: Alfabeta

Peraturan Direktorat Jendral Pendidikan Anak Usia Dini dan Pendidikan Masyarakat No 20 tahun 2019 tentang Teknis Bantuan Pendidikan Kecakapan Kerja

Penyelenggara Uji Kompetensi Bahasa Inggris (UK-BIG).

Susetya, Beni. (2017) Meningkatkan Kemampuan Guru Dalam Menyusun Silabus dan RPP Melalui Supervisi Akademik di SDN Gambiran Yogyakarta Tahun 2016. Jurnal Taman Cendikia. 1(2) hlm134-141

Susanti, Ratna. (2002). Penguasaan Kosa Kata dan Kemampuan Membaca Bahasa Inggris. Jurnal Pendidikan Penabur. 1 (1) hlm. 87-93. 